Special Issue of the 6th International Congress \& Exhibition (APMAS2016), Maslak, Istanbul, Turkey, June 1-3, 2016

\title{
Hydroxyapatite Synthesis from Fish Bones: Atlantic Salmon (Salmon Salar)
}

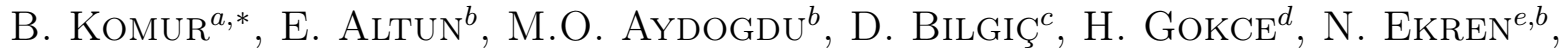

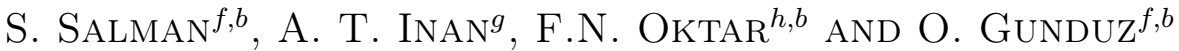 \\ ${ }^{a}$ Department of Orthopaedics and Traumatology, Kanuni Sultan Suleyman Training and Research Hospital, \\ Kucukcekmece, Halkali 34303, Istanbul, Turkey \\ ${ }^{b}$ Advanced Nanomaterials Research Laboratory, Faculty of Technology, Marmara University, \\ Ziverbey, Kadikoy 34722, Istanbul, Turkey \\ ${ }^{c}$ Department of Analytical Chemistry, Faculty of Pharmacy, Marmara University, Istanbul, Turkey \\ ${ }^{d}$ Prof. Dr. Adnan Tekin Material Science and Production Technology Applied Research Centre, \\ Istanbul Technical University, Istanbul, Turkey \\ ${ }^{e}$ Department of Electrical and Electronics Engineering, Faculty of Technology, Marmara University, \\ Ziverbey, Kadikoy 34722, Istanbul, Turkey \\ ${ }^{f}$ Department of Metallurgy and Materials Engineering, Faculty of Technology, Marmara University, \\ Istanbul, Ziverbey, Kadikoy 34722, Turkey \\ ${ }^{g}$ Department of Mechanical Engineering, Faculty of Technology, Marmara University, \\ Ziverbey, Kadikoy 34722, Istanbul, Turkey \\ ${ }^{h}$ Department of Bioengineering, Faculty of Engineering, Marmara University, \\ Ziverbey, Kadikoy 34722, Istanbul, Turkey
}

\begin{abstract}
Production of the bioceramics on the market is presently conducted from typical precipitation method by using reagent grade raw chemicals or through calcination of natural sources like animal bones (especially bovine bone) and fish bones. Usually fish bones were damped near or in the water sources, which can lead to serious environmental pollution. Those were regarded as a trash, even though they still bear economic value, including conjugates. In this study bones of Atlantic Salmon (Salmo salar) were used as a bioceramic material source. Bones of Atlantic Salmon were collected from Besiktas Fish Market. Those were cleaned from possible flesh with reagent grade $\mathrm{NaOH}$. Cleaned parts were washed with demineralized water very neatly. Dry fish bones were calcinated at $850^{\circ} \mathrm{C}$ for 4 hours. The obtained hydroxyapatite material was characterized with scanning electron microscopy and X-ray diffraction methods. It was found that the bioceramic material consisted of hydroxyapatite and various related phases. Scanning electron microscopy studies have revealed nano-structured bioceramic particles. The aim of this study is to obtain nano-structured bioceramics from bones of Atlantic Salmon in an environmentally friendly and economic way.
\end{abstract}

DOI: 10.12693/APhysPolA.131.400

PACS/topics: 87.85.jj, 81.05.-t

\section{Introduction}

Calcium phosphate bioceramics, like hydroxyapatite (HA) is a very popular material for bone reconstruction. The HA bioceramic material makes up to $70 \%$ of bone structure and essentially all of the enamel in teeth. Calcium phosphates can contain several trace elements such as fluorine in enamel HA. HA can be manufactured synthetically from reagent chemicals or can be synthesized from natural resources via hydrothermal transformation, and high temperature calcination from bones.

HA and other bioceramic phases can be obtained through hydrothermal transformation from calcified sources like cuttlefish. With other chemical methods,

*corresponding author; e-mail: barankomur@gmail.com through ultrasonication with mechanical stirring and hot plating, which uses a simple hot plate without mechanical stirring, bioceramics can be obtained from ostrich eggshells [1]. Other calcified or aragonite sources for bioceramic production are corals, barnacles [2], sea mussels, sea urchins [3], sea and land snails.

Bone sources for calcination usually include bovine, sheep, human, and other bones. Besides, experiments with calcination material sources including human, sheep and bovine tooth structures were very successful [4].

Another alternative method to produce HA from bones is to obtain it from various fish species. In one of the previous studies, bioceramics were collected from the Dicentrarchus labrax which is commonly known as European Sea Bass. One of the major phases obtained from this fish corresponds to calcium deficient HA: $\mathrm{Ca} 0 \mathrm{HPO} 4(\mathrm{PO} 4) 5 \mathrm{OH}(\mathrm{Ca} / \mathrm{P}=1.5)$, JCPDS card number 46-0905. Here the $\mathrm{Ca} / \mathrm{P}$ ratio was 1.5 and referred to 
tricalcium phosphate phase (TCP) [5]. In another study HA was prepared from bone materials of three different Brazilian river fishes and calcified at $900^{\circ} \mathrm{C}$ for $4,6,8,10$, and 12 hours [6]. It was also reported production of nano HA particles with dimensions between 24 an $80 \mathrm{~nm}$ [7].

In this study Atlantic Salmon (Salmo salar) was selected as process material for bioceramic production. Since late 1970's, aquaculture of salmon had grown as a very big global industry, producing over 1 million tons per year [8]. It was reported in the latest EU report that the Atlantic Salmon fishes are the salmonid fishes of the temperate and subarctic regions of the North Atlantic. These fishes are showing very strong homing to natal areas to spawn. They are highly variable in their biology within and between locations. Adult fishes range between $\sim 50-120 \mathrm{~cm}$, according to EU reports [9]. It was also reported that salmon stocks are already below the conservation limits because of global warming [10].

It is better to protect the existing population and stop overfishing. According to a very latest study, salmon bearing rivers must be protected, because salmons are dependent on lying eggs in rivers by entering the rivers from sea side [11]. The aim of this study is to obtain and to characterize the HA and related bioceramic phases (i.e. tricalcium phosphate) from waste bony parts of Atlantic Salmon with limited carbon footprint.

\section{Materials and equipment}

Atlantic Salmons were bought at Besiktas Fish Market in Istanbul, Turkey. Fish bones were collected after removing the other flesh parts from the entire fish. Remains of fleshy parts on the bones were cleaned very carefully. Bony parts were treated with reagent grade $\mathrm{NaOH}$. After that bony parts were washed with distilled water. Dry bone remains were calcified for 4 hours at $850^{\circ} \mathrm{C}$. Obtained material appeared in white colour. X-ray diffraction and scanning electron microscopy (SEM) tests have followed out.

\section{Results and discussion}

X-ray diffraction study of raw bone of Atlantic Salmon are shown in Fig. 1a. Major phase consists of $100 \%$ HA (JCPDS card number: 98-009-0501) (it is also called calcium phosphate (v) hydroxide). According to X-ray diffraction studies of calcinated bones in Fig. 1b, major phases for Atlantic Salmon consist from 88.7\% HA (JCPDS card number: 98-006-0425) and from $11.3 \%$ tricalcium bis (orthophosphate) (JCPDS card number 98008-2984). Tricalcium bis (orthophosphate) is called also as TCP according to International Union of Pure and Applied Chemistry (IUPAC) [12]. Tricalcium bis (orthophosphate) with JCPDS card number 98-008-2984 was also found as a minor phase after application of chemical agitation method after $400{ }^{\circ} \mathrm{C}$ and $800^{\circ} \mathrm{C}$ heat treatment of sea snail shells (Atlantic Cowrie - Cypraea cervus Linnaeus) [13].

It was also reported that the tricalcium diorthophosphate beta is the IUPAC name of the "b-tricalcium phosphate" (b-Ca3(PO4)2). Therefore there are several names
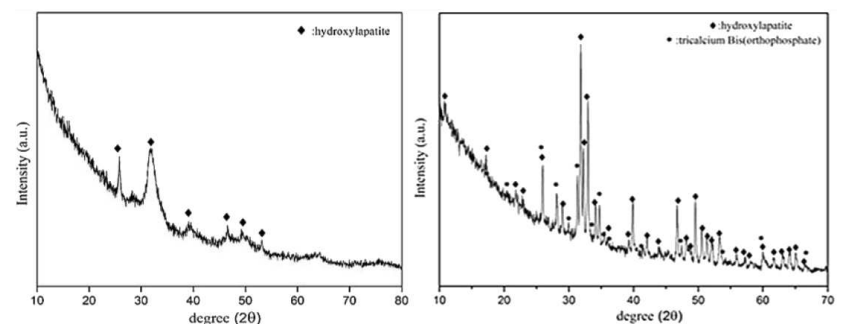

Fig. 1. X-ray diffraction of the (a) raw bone of Atlantic Salmon (Salmo salar), (b) calcinated bone parts of Atlantic Salmon.

available for this compound such as $\mathrm{CaPO} 4$ tribasic beta or tricalcium bis(orthophosphate) beta which is one of the polymorph versions of TCP [14].
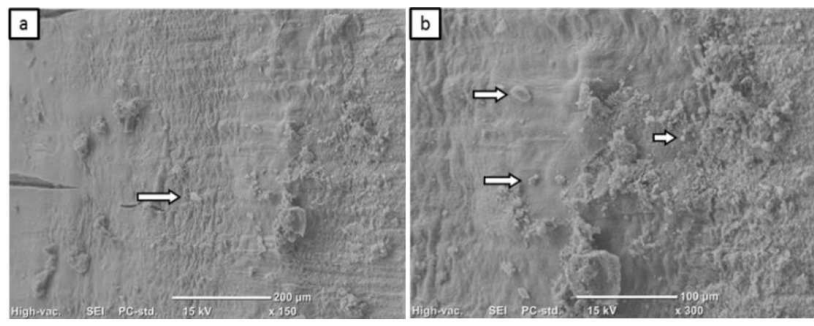

Fig. 2. SEM images (a) $\times 150,(b) \times 300$ taken from upper part of a vertebral column.

In Fig. 2a a small white arrow indicates the bioceramic particle which is about $10 \mu \mathrm{m}$. In Fig. $2 \mathrm{~b}$ upper white arrow indicates a particle of about $12.5 \mu \mathrm{m}$. The middle white arrow shows a very small particle of about $2-3 \mu \mathrm{m}$, while the lower white arrow indicates a relatively bigger particle of about $7-8 \mu \mathrm{m}$. SEM images clearly show that the surface is uneven with small bioceramic particles spread everywhere.

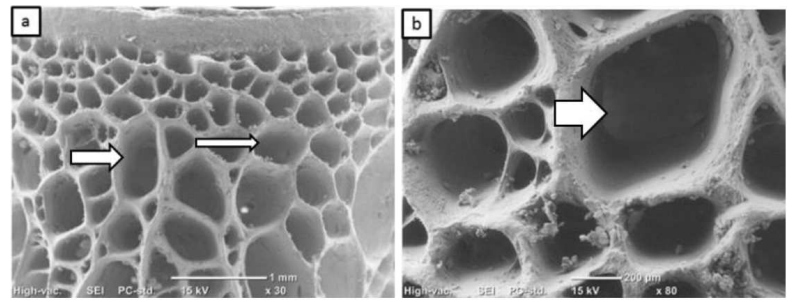

Fig. 3. SEM images taken with $(\mathrm{a}) \times 30(\mathrm{~b}) \times 80 \mathrm{mag}-$ nifications of the cross-section of a piece of a vertebral column.

In Fig. 3a, the biggest pore, shown with a white big arrow, is an ellipsoid with the size of $0.75 \mathrm{~mm}$ along the long axis and $0.50 \mathrm{~mm}$ along the short axis. The second circular porous structure which is shown with smaller thinner white arrow was almost round and had the diameter of about $0.40-0.45 \mu \mathrm{m}$. In Fig. 3b white arrow points that almost rounded porous structure is about $660 \mu \mathrm{m}$. Such level of porosity can be ideal for osseointegration. 
Because the HA phase accounts for $88.7 \%$ and resorbable TCP phase accounts for $11.3 \%$, the dissolution will be slow, and the structures which will pass through these pores will remain for a long time and even very small blood vessels can be formed in these mesoporous structures.

Actually, the macroporous structure had a magnificent scale for osseintegration. Bränemark had made the first very clear definition for osseointegration as: osseointegration is the contact on the light microscope level between living bone tissue and implant [15]. It has been reported that pores $100 \mu \mathrm{m}$ in diameter will serve for successful diffusion of required nutrients and oxygen for cell survivability. However, the pore sizes can be in the range of 200 to $350 \mu \mathrm{m}$. These pore sizes can be optimum for bone tissue in-growth [16].

\section{Conclusions}

In this study, natural HA and TCP phases were obtained by calcination method from the bones of Atlantic Salmon fish. It is one of most important species in seas which has also a very high value for the world market. Ecosystem of the world must be protected, otherwise we will consume without limit this very special fish stock.

This study is a pioneer study for processing natural sourced bioceramics in friendly, noncomplex way without using any harmful chemicals.

\section{Acknowledgments}

This study has been supported by Marmara University (BAPKO Project Number: FEN-C-YLP-250416-0182).

\section{References}

[1] I.J. Macha, L.S. Ozyegin, F.N. Oktar, B. Ben-Nissan, J. Austral. Ceram. Soc. 51, 125 (2015).

[2] F.N. Oktar, H. Gokce, O. Gunduz, Y.M. Sahin, D. Agaogullari, I.G. Turner, L.S. Ozyegin, B. BenNissan, Key Eng. Mater. 631, 137 (2015).
[3] D. Agaogulları, D. Kel, H. Gokce, I. Duman, M.L. Öveçoğlu, A.T. Akarsubasi, D. Bilgic, F.N. Oktar, Acta Phys. Pol. A. 121, 23 (2012).

[4] N. Akyurt, M. Yetmez, U. Karacayli, O. Gunduz, S. Agathopoulos, H. Gokce, M.L. Öveçoğlu, F.N. Oktar. Key Eng. Mater. 493, 281 (2012).

[5] Y.M. Sahin, O. Gunduz, A. Ficai, N. Ekren, A. Tuna, A.T. Inan, F.N. Oktar, Key Eng. Mater. 696, 60 (2016).

[6] T.M. Coelho, E.S. Nogueira, A. Steimacher, A.N. Medina, W.R. Weinand, W.M. Lima, M.L. Baesso, A.C. Bento, J. App. Phys. 100, 094312 (2006).

[7] T.M. Coelho, E.S. Nogueira, W.R. Weinand, W.M. Lima, A. Steimacher, A.N. Medina, M.L. Baesso, A.C. Bento, J. App. Phys. 101, 084701 (2007).

[8] J.S. Ford, R.A. Myers, PLoS Biol. 6, 0411 (2008).

[9] E. Verspoor, I. Olesen, H.B. Bentsen, K. Glover, P. McGinnity, A. Norris, in: Genetic impact of aquaculture activities on native populations, Eds. T. Svåsand, D. Crosetti, E. García-Vázquez, E. Verspoor, European Commission, 2007, p. 23.

[10] M.L. Windsor, P. Hutchinson, L.P. Hansen, D.G. Reddin, Atlantic Salmon at sea: Findings from recent research and their implications for management, NASCO, Edinburgh 2012.

[11] World Wildlife Fund, The Status of Wild Atlantic Salmon: A River by River Assessment, 2001.

[12] H.A. Favre, W.H. Powell, Nomenclature of Organic Chemistry: IUPAC Recommendations and Preferred Names 2013, Ser.: International Union of Pure and Applied Chemistry, 1st ed., Royal Society of Chemistry, 2013.

[13] O. Gunduz, Y.M. Sahin, S. Agathopoulos, D. Ağaoğulları, H. Gökçe, E.S. Kayali, C. Aktas, B. BenNissan, F.N. Oktar, Key Eng. Mater. 587, 80 (2014).

[14] S. Dorozhkin, Ceram. Int. 41, 13913 (2015).

[15] J.W. Harrison, Cleft Palate-Craniofacial J. 29, 485 (1992).

[16] S. Bose, M. Roy, A. Bandyopadhyay, Trends Biotechnol. 30, 546 (2012). 